This is an electronic reprint of the original article. This reprint may differ from the original in pagination and typographic detail.

Author(s): Portegijs, Erja; Sipilä, Sarianna; Alen, Markku; Kaprio, Jaakko; Koskenvuo, Markku; Tiainen, Kristina; Rantanen, Taina

Title: $\quad$ Leg extension power asymmetry and mobility limitation in healthy older women

Year: $\quad 2005$

Version:

Please cite the original version:

Portegijs, E., Sipilä, S., Alen, M., Kaprio, J., Koskenvuo, M., Tiainen, K., \& Rantanen, T. (2005). Leg extension power asymmetry and mobility limitation in healthy older women. Archives of Physical Medicine and Rehabilitation, 86, 1832-1842.

All material supplied via JYX is protected by copyright and other intellectual property rights, and duplication or sale of all or part of any of the repository collections is not permitted, except that material may be duplicated by you for your research use or educational purposes in electronic or print form. You must obtain permission for any other use. Electronic or print copies may not be offered, whether for sale or otherwise to anyone who is not an authorised user. 
Published in Archives of Physical Medicine and Rehabilitation vol 86, Issue 9, 1838-1842. DOI: http://dx.doi.org/10.1016/j.apmr.2005.03.012

\section{Leg Extension Power Asymmetry and Mobility Limitation in Healthy Older Women}

Erja Portegijs ${ }^{1}$, MSc, Sarianna Sipilä ${ }^{1,2}, \mathrm{PhD}$, Markku Alen ${ }^{3}$, MD PhD, Jaakko Kaprio ${ }^{4,5}$, MD PhD, Markku Koskenvuo ${ }^{6}$, MD PhD, Kristina Tiainen ${ }^{1}$, MSc, Taina Rantanen ${ }^{1,2}$, PhD

${ }^{1}$ Department of Health Sciences, University of Jyväskylä, Jyväskylä, Finland

${ }^{2}$ The Finnish Centre for Interdisciplinary Gerontology, University of Jyväskylä, Jyväskylä,

Finland

${ }^{3}$ Kuopio Research Institute of Exercise Medicine, Kuopio, Finland

${ }^{4}$ Department of Public Health, University of Helsinki, Helsinki, Finland

${ }^{5}$ Department of Mental Health and Alcohol Research, National Public Health Institute, Helsinki, Finland

${ }^{6}$ Department of Public Health, University of Turku, Turku, Finland

Corresponding Author: Erja Portegijs

Department of Health Sciences, University of Jyväskylä,

P.O. Box 35 (Viv), FI-40014 Jyväskylä Finland

Phone: +358 14260 2175, and GSM: + 358400410480

Fax: +358 14260 4600, and E-mail: erja.portegijs@ sport.jyu.fi

Short running head: LEP asymmetry and mobility in old women 
1 Leg Extension Power Asymmetry and Mobility Limitation in Healthy Older Women

\section{ABSTRACT}

4

5 Objective: The aim of this study was to investigate the association of asymmetry in leg

6 extension power (LEP) with walking and standing balance.

7 Design: Cross-sectional analysis

8 Setting: Research-laboratory

9 Participants: 419 healthy 63-75-year-old female twins

10 Measures: The LEP difference between the stronger and weaker leg, measured with the

11 Nottingham power-rig, was calculated. 10-meter maximal walking velocity was assessed in a

12 laboratory corridor on a wide and narrow track $(35 \mathrm{~cm})$, and the ability to maintain tandem

13 stance for 20 seconds was recorded.

14 Results: The mean LEP difference between the legs was $15 \%$, SD 9\%. Those with large LEP

15 difference had lower walking velocity and poorer standing balance than those with small LEP

16 difference, in particular when LEP of the stronger leg was below the median.

17 Conclusions: Even in healthy older women, substantial LEP asymmetry between the lower

18 limbs was present encumbering walking and standing balance. Lower limb muscle power

19 asymmetry warrants further study in order to develop well-targeted strategies for the prevention

20 of mobility limitation in older people.

21

22 Keywords: LEP, asymmetry, mobility function, older women 
3 Age-related decreases in muscle strength and contraction velocity cause muscle power in older

4 people to deteriorate ${ }^{1-3}$, potentially leading to mobility limitation, loss of independence and

5 disability ${ }^{4-7}$. In research on the association between muscle power and mobility measures, such

6 as walking speed, power of the stronger leg, average or total muscle power of both legs have

7 often been the measures used..$^{2,4,8,9}$ Even though neuromuscular asymmetry, such as difference in

8 muscle power between the lower limbs, is a common and harmless feature in young and healthy

9 people, there are indications that it may affect mobility in older and frail people. In a clinical

10 population with extremely large power asymmetry in the lower limbs, muscle power of the

11 weaker leg rather than the stronger leg was a powerful predictor of mobility. ${ }^{10}$ In addition, a

12 study by Skelton et al. ${ }^{11}$ indicated that power asymmetry was a strong predictor of falls. The

13 difference in muscle power between the legs may therefore be important to take into account

14 when investigating mobility in older people.

The aim of this study was to determine the extent of asymmetry in leg extension power (LEP) in a group of relatively healthy older women. In addition, the associations of LEP of the stronger, weaker and difference between two legs with walking and standing balance were investigated.

19 We hypothesised that large LEP asymmetry is associated with lower walking velocity and poorer 20 standing balance, especially in people with low muscle power. Additionally, we expected that 21 LEP of the weaker leg to be a better predictor of walking velocity and standing balance than LEP 22 of the stronger leg and that asymmetry would become a limiting factor in challenging situations 23 like walking on a narrow track or standing in a tandem position. 


\section{METHODS}

\section{Participants}

4 This study is part of the Finnish Twin Study on Aging (FITSA), a study of genetic and

5 environmental effects on the disablement process in older, 63-75-years-old, female twins with

6101 mono- and 116 dizygotic twin pairs participating in the laboratory examinations $(\mathrm{N}=434)$.

7 To be recruited for the study, both twin sisters had to agree to participate. A detailed description

8 of the study design and recruitment has been reported elsewhere. ${ }^{12}$ In total 419 women

9 participated in the laboratory tests reported.

10

11 Before the laboratory examinations, the participants were informed about the study and written

12 informed consent was obtained. The study was approved by the Ethics Committee of the Central

13 Hospital of Central Finland.

15 Health ascertainment

16 First, all participants underwent a 30-minute clinical examination by a physician. Self-reports of 17 acute and chronic diseases and medication had been obtained earlier and were confirmed by the 18 physician. Chronic diseases, present for at least 3 months, included in the analyses were

19 cardiovascular diseases (such as ischemic heart disease and hypertension), respiratory diseases

20 (such as asthma and bronchitis), neurological diseases (such as epilepsy and cerebrovascular

21 dysfunction), musculoskeletal diseases (such as knee, hip and foot osteoarthritis), rheumatic

22 diseases, hormonal diseases (such as diabetes and thyroid gland dysfunction), liver or kidney

23 diseases, and cancer. The number of chronic diseases was calculated as a measure of co- 
1 morbidity. Contraindications for muscle power testing were checked separately for each leg.

2 Factors, such as pain (painful arthritis) or limitations in joint range of motion (endoprostheses), making satisfactory muscle power measurement impossible were considered for exclusion.

4 Additionally, acute and severe conditions, such as recent myocardial infarction, and poor cooperation were considered contraindications for participation in the muscle power, walking or

6 balance tests.

Self-reported presence of pain in the hip, knee, ankle and foot on most days for at least one month during the preceding year was measured with a yes (score 1) or no (score 0 ) question. A

10 sum index of pain, ranging from 0 to 4 , was created as a measure of wide spread pain in the 11 lower extremities

\section{Muscle power}

14 LEP, expressed in Watts (W), was measured on both sides using the Nottingham power-rig ${ }^{13}$, unless the physician observed contraindications to participate in the power assessment on one $(\mathrm{N}=31)$ or both sides $(\mathrm{N}=15)$. For each leg, the seat position was adjusted for leg length to allow the leg to reach full extension at the end of the movement. Muscle power of the leg on the side of the dominant hand was tested first. During testing, the participant was seated with the arms folded, one foot was placed on the pedal attached to a flywheel, the other foot rested on the floor. After two to three practise trials, the participant was asked to push the pedal as hard and fast as possible. The measurement was repeated until no further improvement occurred, but at least 5 times. The inter-trial rest period was 30 seconds. The best performance was used as the measure of maximal power of the respective leg. The muscle power measurement with the Nottingham 
1 power rig has been validated and found to be safe and acceptable among older people. ${ }^{13}$ The testretest coefficient of variation for this population in our laboratory is $8 \%$.

\section{$4 \quad$ Maximal walking speed}

5 Maximal walking speed over 10 meters was measured in a laboratory corridor (wide track) and 6 on a $35 \mathrm{~cm}$ track (narrow) marked on the floor. The participants were instructed to walk as fast

7 as possible, without compromising safety. Maximal walking speed has been predictive of

8 functional dependence ${ }^{14}$ and mortality ${ }^{15}$. The participants were allowed 3 meters for acceleration.

9 Time was measured automatically using photocells. The participants were allowed one trial on

10 the narrow track and two trials on the wide track (the faster performance was recorded). The

11 participants wore walking shoes or sneakers and the test order was the same for each participant

12 and the resting time between the tests was 1 minute. The test-retest coefficient of variation in our

13 laboratory for this population is $5 \%$.

\section{Standing balance}

16 The standing balance tests were performed with the participant in stocking feet. During the tests,

17 the participants were instructed to stand as still as possible in a well-balanced position. The

18 ability of the participant to maintain balance for 20 seconds in semi-tandem and tandem position

19 was recorded. The semi-tandem position was performed with one foot placed one-half a foot-

20 length ahead of the other, with the feet touching. In the tandem position one foot was placed in

21 front of the other with the feet touching. Tandem stance is frequently used in physical

22 performance tests such as the Berg balance-scale ${ }^{16}$ and lower extremity function tests used in

23 EPESE studies ${ }^{17}$. The participants were asked to keep their arms down by their sides. Gaze was 
1 fixed at a marked point at eye level at a distance of 2 meters. Timing started when a balanced and

2 safe stance had been attained. The participants were allowed one trial for each test. Correcting a

3 disturbance in balance by moving a foot or leg, or reaching for support with hands was regarded

4 as inability to maintain balance. The tests were performed in the same order, from easier to more

5 difficult, for all participants. They were allowed to sit down and rest for one minute between the 6 tests.

\section{Anthropometry}

9 Body height and weight were measured in the laboratory. Lean body mass and total body fat 10 were assessed using bioelectrical impedance (Spectrum II; RJL Systems, Detroit; MI, U.S.A)

11 using the manufacturer's equation. The coefficient of variation between two consecutive 12 measurements in our laboratory was $<2 \%$ for LBM and $<3 \%$ for body fat mass. ${ }^{18}$

\section{Physical activity}

15 A self-report scale by Grimby ${ }^{19}$ with slight modifications was used to assess the present status of 16 physical activity. The highest category of the initial scale was divided into two categories 17 separating those participating in regular exercise fitness activities from those active in 18 competitive sports. The 7-point scale ranged from 1 (hardly any activity) to 7 (participation in 19 competitive sports). People were considered sedentary if they reported no other activity than 20 light walking once or twice a week.

\section{Statistical analysis}


1 Among those with LEP measured on both sides, the difference in LEP between the stronger and

2 weaker leg was calculated. To obtain the relative LEP difference, the absolute LEP difference

3 was divided by LEP of the stronger leg and then multiplied by $100 \%$. Participants belonging to

4 the tertile with the largest LEP difference $(\geq 17 \mathrm{~W})$ and participants with LEP measured in one

5 leg only, were considered to have a large asymmetry. Participants with LEP of the stronger leg

6 below median $(97 \mathrm{~W})$ were considered to have poor LEP.

8 Although the sample consists of twins, no within pair analyses were carried out. The sample was

9 treated as a set of individuals by taking into account the dependency between the sisters.

11 All statistical analyses were run on SPSS 11.0 software (SPSS Inc.; Chicago; IL, USA). Group

12 specific marginal means and $95 \%$ confidence intervals of each continuous variable were

13 calculated with general linear univariate analyses of variance with the twin pair variable as a

14 random effects factor, which adjusted for the dependency between the sisters. The adjusted

15 values were saved and used for further analysis. Categorical variables were entered in the

16 analyses without adjustment. Kruskal-Wallis tests were used to assess group differences for the

17 categorical variables. The associations between walking velocity and the LEP measures were

18 analysed with partial correlation and the group differences were analysed using a general linear

19 multivariate analysis (two-way ANOVA). The tandem stance ability was analysed with a general

20 linear univariate analysis to compare the muscle power measures among those able and unable to

21 maintain tandem stance. Additionally, a logistic regression was performed to assess the risk of

22 inability to maintain tandem stance. The analyses were adjusted for age, body weight and body 
1 height. Standing balance in semi-tandem position could not be analysed as only 2 participants

2 were unable to maintain balance. Significance was set at $P<0.05$ for all tests.

3 
RESULTS

3 Mean LEP of the stronger leg was $100.2 \mathrm{~W}$, SD $30.3 \mathrm{~W}$, and that of the weaker leg $86.3 \mathrm{~W}$, SD

$428.1 \mathrm{~W}$. The relative LEP difference between the stronger and weaker leg was on average $15 \%$, $5 \quad \operatorname{SD} 9 \%(\mathrm{p}<0.001)$.

7 The women with poor LEP were somewhat older and had a lower lean body mass than the other

8 participants (Table 1). Physical inactivity was more common among women with poor LEP.

9 Among those with poor LEP, $41 \%$ of those with large asymmetry were sedentary and $31 \%$ of

10 those with small asymmetry compared to about $20 \%$ of the other participants. The prevalence of

11 any disease, category of diseases or pain in the lower extremities did not differ among the 12 participants.

14 After adjustment for age, body height and body weight, high LEP of the stronger and weaker leg was associated with faster walking velocity ( $\mathrm{r}=0.45, P<0.001$ and $\mathrm{r}=0.48, P<0.001$, respectively). Additionally, the larger the relative difference in power between the legs, the slower the walking speed $(\mathrm{r}=-0.23, P<0.001)$. The results were similar on the narrow track.

19 Figure 1 shows the mean walking velocity on the wide and narrow track in the groups based on LEP of the stronger leg and the asymmetry. Walking velocity was highest among those with high

21 LEP and small asymmetry and decreased with decreasing LEP and increasing asymmetry.

22 Multivariate analysis showed that, after adjustment for age, body height and body weight, the 23 categorized variables of LEP of the stronger leg $(P<0.001$ and $P<0.001)$ and the asymmetry 
$1 \quad(P=0.027$ and $P=0.016)$ were independent predictors of walking velocity without an interaction

2 effect $(P=0.573$ and $P=0.484)$ on the wide and narrow track, respectively. Similar results were

3 obtained when the participants with LEP measured in one leg only were not included in the

4 analysis.

5

6 In total, 50 participants ( $12 \%$ of the sample) were unable to maintain tandem stance for 20

7 seconds. After adjustment for age, body height and body weight, those able to maintain tandem

8 stance had higher LEP and a lower relative LEP difference than the other participants (Table 2).

9 Figure 2 shows the distribution of those able to maintain tandem stance over the groups based on

10 LEP of the stronger leg and the asymmetry. Additionally, logistic regression analysis revealed

11 that for participants with poor LEP, the risk for inability to maintain tandem stance was 5.5-fold

12 (95\% confidence interval: $2.3-13.3)$ in those with large asymmetry and 2.8-fold higher (95\%

13 confidence interval: 1.2-6.4) in those with small asymmetry compared to the risk among those

14 with high LEP and small asymmetry (reference group). Among those with high LEP, asymmetry

15 was not associated with an increased risk. Similar results were obtained when the participants

16 with LEP measured in one leg only were not included in the analysis. 


\section{DISCUSSION}

3 This study showed that, even among healthy older women, the mean power difference between

4 the stronger and weaker leg was approximately 15\%. Large leg extension power asymmetry,

5 particularly when accompanied with general poor power was associated with poor walking

6 velocity and standing balance. Skelton et al. ${ }^{11}$ reported similar levels of muscle power and

7 muscle power asymmetry among older community-dwelling women with a history of repeated

8 falls. Additionally, poor muscle strength ${ }^{20}$ and power ${ }^{10}$ of the affected leg was associated with

9 lower walking velocity among hip fracture patients. To the best of our knowledge, the

10 association between muscle power asymmetry and mobility limitation has not been studied in a

11 general population. However, our findings indicate that power asymmetry may be an important

12 determinant of mobility also in healthy populations.

14 Although neuromuscular asymmetry is common, diseases and pain, a potential precursor of a 15 disease, affecting the lower limbs unilaterally potentially cause large asymmetry. Previous

16 unilateral musculoskeletal injury may cause large asymmetry as well, even in the long-term. ${ }^{20-23}$

17 In the current study, asymmetry was not associated with any disease, category of diseases,

18 number of diseases, or prevalence of pain in the lower extremities. Unfortunately, information

19 about prior injuries was not available.

21 General muscle power affected walking and standing balance in this study. In addition, muscle 22 power asymmetry affected mobility too, especially in the presence of low muscle power. This 23 may be related to the high correlation between muscle power and mobility when power is 
1 approximating the threshold level of a certain task. ${ }^{4,24}$ In addition, this may explain why, in our

2 study among relatively healthy women, muscle power affected balance only in the most

3 challenging tandem balance task. In the current data, correlations between the weaker and the

4 stronger leg and mobility limitation did not materially differ, however, they were slightly

5 stronger for the weaker leg. As the correlation between muscle power and mobility is strongest

6 among people with impairments, muscle power of the weaker leg may be a better predictor of

7 mobility in populations with lower muscle power and/or larger asymmetry. In a clinical

8 population muscle power of the weaker leg potentially indicates the severity of the condition

9 affecting the leg. The role of muscle power asymmetry on future mobility limitation or fall risk,

10 independent of disease or injury, warrants further study.

11

12 Strength and power training are effective strategies to increase muscle power ${ }^{25-27}$ and to improve

13 mobility ${ }^{26-27}$ among older people. This study suggests that muscle power asymmetry should be

14 taken into account in physical training programs aiming to improve mobility function. Training

15 protocols aiming to decrease asymmetry may improve mobility in older people more than

16 training solely focussing on an increase in general muscle power.

18 It is especially important to investigate the underlying causes of the mobility limitation in older

19 women, as mobility limitations are more common among older women than men. ${ }^{28}$ Additionally, 20 the ability to generate force quickly is important for many daily activities and for prevention of a

21 fall. $4,9,11,29,30$ 
1 The study population was composed of relatively healthy and mobile older women. To be

2 recruited for the present study, the participants had to be able to travel independently to the 3 research laboratory. People with poor mobility and possibly related impairments were more

4 likely to drop out, which, at least to some extent, reduced the variance in muscle power, walking 5 velocity and standing balance. The effects of low muscle power and/or large asymmetry may be 6 more pronounced among people less healthy and with more severe mobility limitations.

7 Generalising the results of this study should therefore happen with caution. The results of the 8 current cross-sectional analysis need to be confirmed in prospective and experimental studies. 9 


\section{CONCLUSIONS}

2

3 This study indicated that substantial muscle power asymmetry was present among healthy older

4 women. In addition to general low muscle power, muscle power asymmetry in the lower limbs

5 was associated with impaired mobility. The asymmetry affected walking velocity and standing

6 balance in this population, especially in the presence of low muscle power and in more

7 challenging situations. Muscle power asymmetry warrants further study in order to develop well-

8 targeted strategies for the prevention of mobility limitation in older people.

9 


\section{ACKNOWLEDGMENTS}

2

3 This study was supported by Juho Vainion Säätiö, Finnish Cultural Foundation and Academy of

4 Finland. 


\section{REFERENCES}

1. Izquierdo M, Ibanez J, Gorostiaga E, Garrues M, Zuniga A, Anton A et al. Maximal strength and power characteristics in isometric and dynamic actions of the upper and lower extremities in middle-aged and older men. Acta Physiol Scand. 1999;167:57-68.

2. Lauretani F, Russo CR, Bandinelli S, Bartali B, Cavazzini C, Di Iorio A et al. Ageassociated changes in skeletal muscles and their effect on mobility: an operational diagnosis of sarcopenia. J Appl Physiol. 2003;95:1851-60.

3. De Vito G, Bernardi M, Forte R, Pulejo C, Macaluso A, Figura F. Determinants of maximal instantaneaous muscle power in women aged 50-75 years. Eur J Appl Physiol. 1998;78:59-64.

4. Bean JF, Kiely DK, Herman S, Leveille SG, Mizer K, Frontera WR et al. The relationship between leg power and physical performance in mobility-limited older people. J Am Geriatr Soc. 2002;50:461-7.

5. Bean JF, Leveille SG, Kiely DK, Bandinelli S, Guralnik JM, Ferrucci L. A comparison of leg power and leg strength within the InCHIANTI study: Which influences mobility more? J Gerontol Med Sci. 2003;58A:728-33.

6. Rantanen T, Guralnik JM, Sakari-Rantala R, Leveille S, Simonsick EM, Ling S et al. Disability, physical activity, and muscle stregnth in older women: the women's health and aging study. Arch Phys Med Rehabil. 1999;80:130-5.

7. Rantanen T, Avlund K, Suominen H, Schroll M, Frandin K, Pertti E. Muscle strength as a predictor of onset of ADL dependence in people aged 75 years. Aging Clin Exp Res. 2002;14:10-5. 
8. Foldvari M, Clark M, Laviolette LC, Bernstein MA, Kaliton D, Castaneda C et al. Association of muscle power with functional status in community-dwelling elderly women. J Gerontol Med Sci. 2000;55A:M192-9.

9. Suzuki T, Bean JF, Fielding RA. Muscle power of the ankle flexors predicts functional performance in community-dwelling older women. J Am Geriatr Soc. 2001;49:1161-7.

10. Lamb SE, Morse RE, Evans JG. Mobility after proximal femoral fracture: the relevance of leg extensor power, postural sway and other factors. Age and Ageing. 1995;24:308-14.

11. Skelton DA, Kennedy J, Rutherford OM. Explosive power and asymmetry in leg muscle function in frequent fallers and non-fallers. Age and Ageing. 2002;31:119-25.

12. Tiainen K, Sipilä S, Alen M, Heikkinen E, Kaprio J, Koskenvuo M et al. Heritability of maximal isometric muscle strength in older female twins. J Appl Physiol. 2004;96:173-80.

13. Bassey EJ, Short AH. A new method for measuring power output in a single leg extension: feasibility, reliability and validity. Eur J Appl Physiol. 1990;60:385-90.

14. Shinkai A, Watanabe S, Kumigai S, Fujiwara Y, Amano H, Yoshida H et al. Walking speed as a good predictor for the onset of functional dependence in a Japanese rural community population. Age Ageing 2000;29:441-6.

15. Laukkanen P, Heikkinen E, Kauppinen M. Muscle strength and mobility as predictors of survival in 75-84-year-old people. Age Ageing 1995;24:468-73.

16. Berg KO, Wood-Dauphinee SL, Williams JI, Maki B. Measuring balance in the elderly: validation of an instrument. Can J Public Health 1992;83(Suppl 2):S7-11.

17. Guralnik JM, Ferrucci L, Pieper CF, Leveille SG, Markides KS, Ostir GV et al. Lower extremity function and subsequent disability: Consistency across studies, predictive 
models, and value of gait speed alone compared with the short physical performance battery. J Gerontol Med Sci 2000;55A:M221-31.

18. Sipilä S, Multanen J, Kallinen M, Era P, Suominen H. Effects of strength and endurance training on isometric muscle strength and walking speed in elderly women. Acta Physiol Scand. 1996;156:457-64.

19. Grimby G. Physical activity and muscle training in the elderly. Acta Med Scand. 1986;711(suppl):233-7.

20. Madsen OR, Laudrisen UB, Sørensen OH. Quadriceps strength in women with a previous hip fracture: relationship to physical ability and bone mass. Scand J Rehabil Med. $2000 ; 32: 37-40$.

21. Holder-Powell HM, Rutherford OM. Unilateral lower limb injury: its long-term effects on quadriceps, hamstring, and plantar flexor muscle strength. Arch Phys Med Rehabil. 1999;80:717-20.

22. Holder-Powell HM, Rutherford OM. Unilateral lower limb musculoskeletal injury: it longterm effect on balance. Arch Phys Med Rehabil. 2000;81:265-8.

23. Honkonen SE, Kannus P, Natri A, Latvala K, Järvinen MJ. Isokinetic performance of the thigh muscels after tibial plateau fractures. Int Orthop. 1997;21:323-6.

24. Rantanen T and Avela J. Leg extension power and walking speed in very old people living independently. J Gerontol Med Sci. 1997;52A:M225-31.

25. Fielding RA, LeBrasseur NK, Cuoco A, Bean J, Mizer K, Fiatarone Singh MA. Highvelocity resistance training increases skeletal muscle peak power in older women. J Am Geriatr Soc. 2002;50:655-62. 
26. Hruda KV, Hicks AL, McCartney. Training for muscle power in older adults: effects on functional abilities. Can J Appl Physiol. 2003;28:178-89.

27. Sayers SP, Bean J, Cuoco A, LeBrasseur NK, Jette A, Fielding RA. Changes in function and disability after resistance training: does velocity matter? Am J Phys Med Rehabil. 2003;82:605-13.

28. Fried LP, Guralnik JM. Disability in older adults: evidence regarding significance, etiology, and risk. J Am Geriatr Soc. 1997;45:92-100.

29. Evans WJ. Editorial: Exercise strategies should be designed to increase muscle power. J Gerontol Med Sci. 2000;55A:M309-10.

30. Izquierdo M, Aguada X, Gonzalez R, Lopez JL, Häkkinen K. Maximal and explosive force production capacity and balance performance in men of different ages. Eur J Appl Physiol. 1999;79:260-7. 
Table 1. Means and 95\% confidence intervals (95\% CI) of the characteristics of women with LEP of the stronger leg above (high

LEP) or below (poor LEP) median and small or large (those in the tertile with the highest absolute LEP difference between the legs and those with LEP measured on one side only) asymmetry.

\begin{tabular}{|c|c|c|c|c|c|c|c|c|c|}
\hline & \multicolumn{4}{|c|}{ Poor LEP } & \multicolumn{4}{|c|}{ High LEP } & \multirow{4}{*}{$\begin{array}{r}\text { Equality } \\
\text { of Means } \\
\text { Test } \\
P\end{array}$} \\
\hline & \multirow{2}{*}{\multicolumn{2}{|c|}{$\begin{array}{l}\text { Large Asymmetry } \\
\qquad \mathrm{n}=73\end{array}$}} & \multirow{2}{*}{\multicolumn{2}{|c|}{$\begin{array}{l}\text { Small Asymmetry } \\
\qquad n=133-134\end{array}$}} & \multirow{2}{*}{\multicolumn{2}{|c|}{$\begin{array}{l}\text { Large Asymmetry } \\
\qquad \mathrm{n}=96\end{array}$}} & \multirow{2}{*}{\multicolumn{2}{|c|}{$\begin{array}{l}\text { Small Asymmetry } \\
\qquad n=116\end{array}$}} & \\
\hline & & & & & & & & & \\
\hline & Mean & $95 \% \mathrm{CI}$ & Mean & $95 \% \mathrm{CI}$ & Mean & $95 \% \mathrm{CI}$ & Mean & $95 \% \mathrm{CI}$ & \\
\hline Age (year) & 68.8 & $68.0-69.7$ & 69.3 & $68.7-69.9$ & 68.0 & $67.3-68.7$ & 68.0 & $67.5-68.6$ & 0.004 \\
\hline Body Weight (kg) & 68.5 & $66.5-70.5$ & 67.8 & $66.2-69.3$ & 71.9 & $70.2-73.7$ & 71.7 & $70.0-73.3$ & 0.091 \\
\hline Body Height (cm) & 157.7 & $157.0-158.5$ & 157.0 & $156.5-157.6$ & 160.0 & $159.3-160.7$ & 160.1 & $159.5-160.7$ & 0.047 \\
\hline Lean Body Mass (kg) & 44.8 & $43.9-45.6$ & 44.4 & $43.7-45.0$ & 47.5 & $46.8-48.2$ & 47.5 & $46.8-48.2$ & 0.001 \\
\hline Total Body Fat (kg) & 23.7 & $22.3-25.2$ & 23.4 & $22.3-24.5$ & 24.0 & $22.8-25.3$ & 24.8 & $23.0-25.3$ & 0.436 \\
\hline Number of Diseases (n) & 2.4 & $2.2-2.7$ & 2.5 & $2.3-2.7$ & 2.4 & $2.2-2.6$ & 2.2 & $2.1-2.4$ & 0.295 \\
\hline
\end{tabular}


Table 2 . The marginal means and $95 \%$ confidence intervals $(95 \% \mathrm{CI})$ of the respective LEP measure for women able and unable to maintain tandem stance, obtained with an univariate analysis of variance with adjustment for age, body weight and body height.

\begin{tabular}{|c|c|c|c|c|c|}
\hline & \multicolumn{2}{|c|}{ Able to Maintain } & \multicolumn{2}{|c|}{ Unable to Maintain } & Equality of \\
\hline & \multicolumn{2}{|c|}{ Balance } & \multicolumn{2}{|c|}{ Balance } & Means Test \\
\hline & Mean & $95 \% \mathrm{CI}$ & Mean & $95 \% \mathrm{CI}$ & $P$ \\
\hline LEP of the weaker leg (W) & 89.9 & $87.1-92.7$ & 72.6 & $66.1-79.2$ & $<0.001$ \\
\hline LEP of the stronger leg $(W)$ & 104.4 & $101.4-107.4$ & 89.2 & $82.2-96.3$ & $<0.001$ \\
\hline Relative LEP difference (\%) & 14.3 & $13.3-15.2$ & 18.6 & $16.4-20.8$ & $<0.001$ \\
\hline
\end{tabular}


Figure 1. The mean walking velocity and $95 \%$ confidence intervals on the wide and narrow track in women with LEP of the stronger leg above (high LEP) or below (poor LEP) median and small or large (those in the tertile with the highest absolute LEP difference between the legs and those with LEP measured on one side only) asymmetry. 
Figure 2. The proportion of participants able to maintain tandem stance in the groups of women with LEP of the stronger leg above (high LEP) or below (poor LEP) median and small or large (those in the tertile with the highest absolute LEP difference between the legs and those with LEP measured on one side only) asymmetry. 


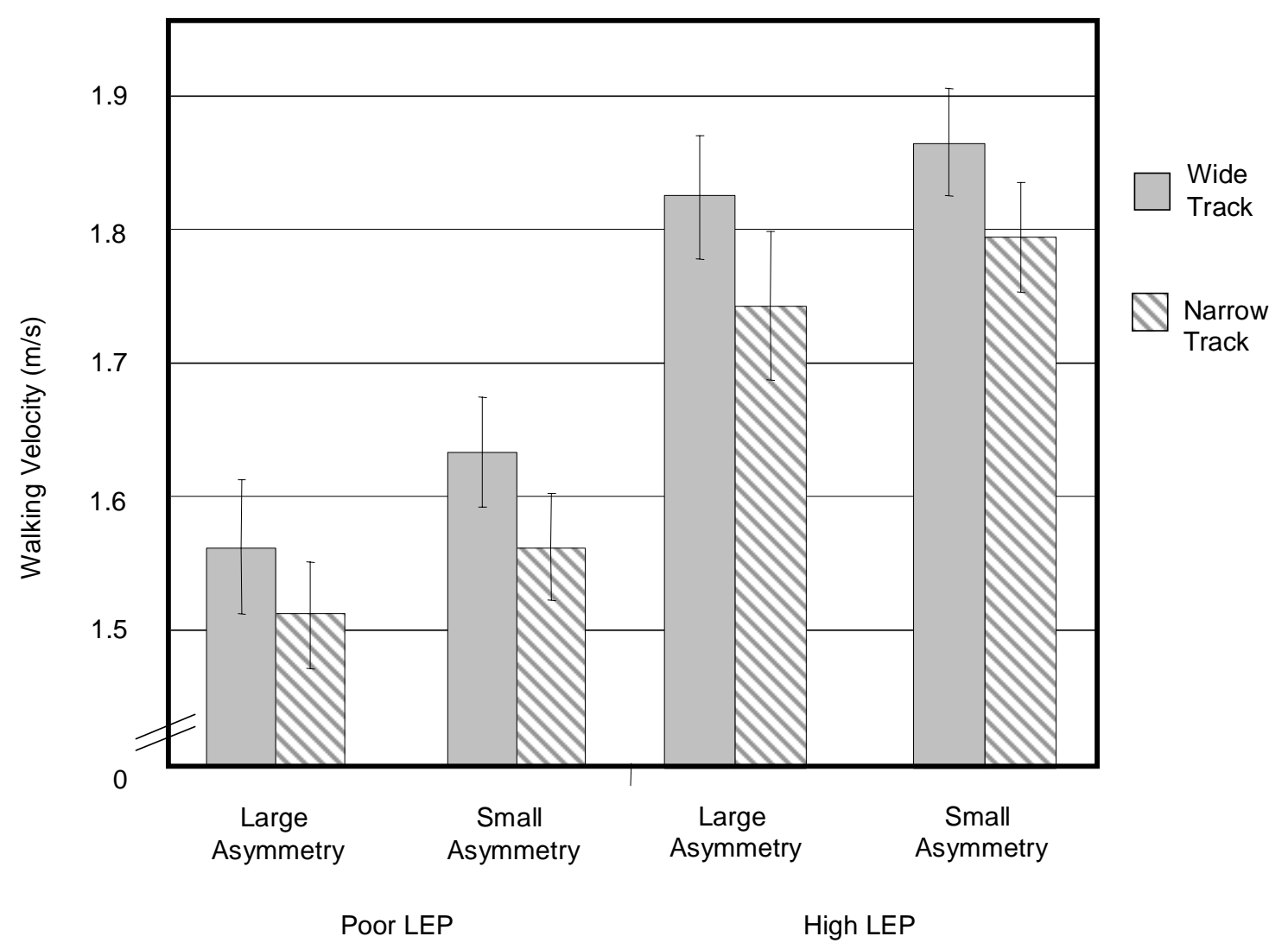




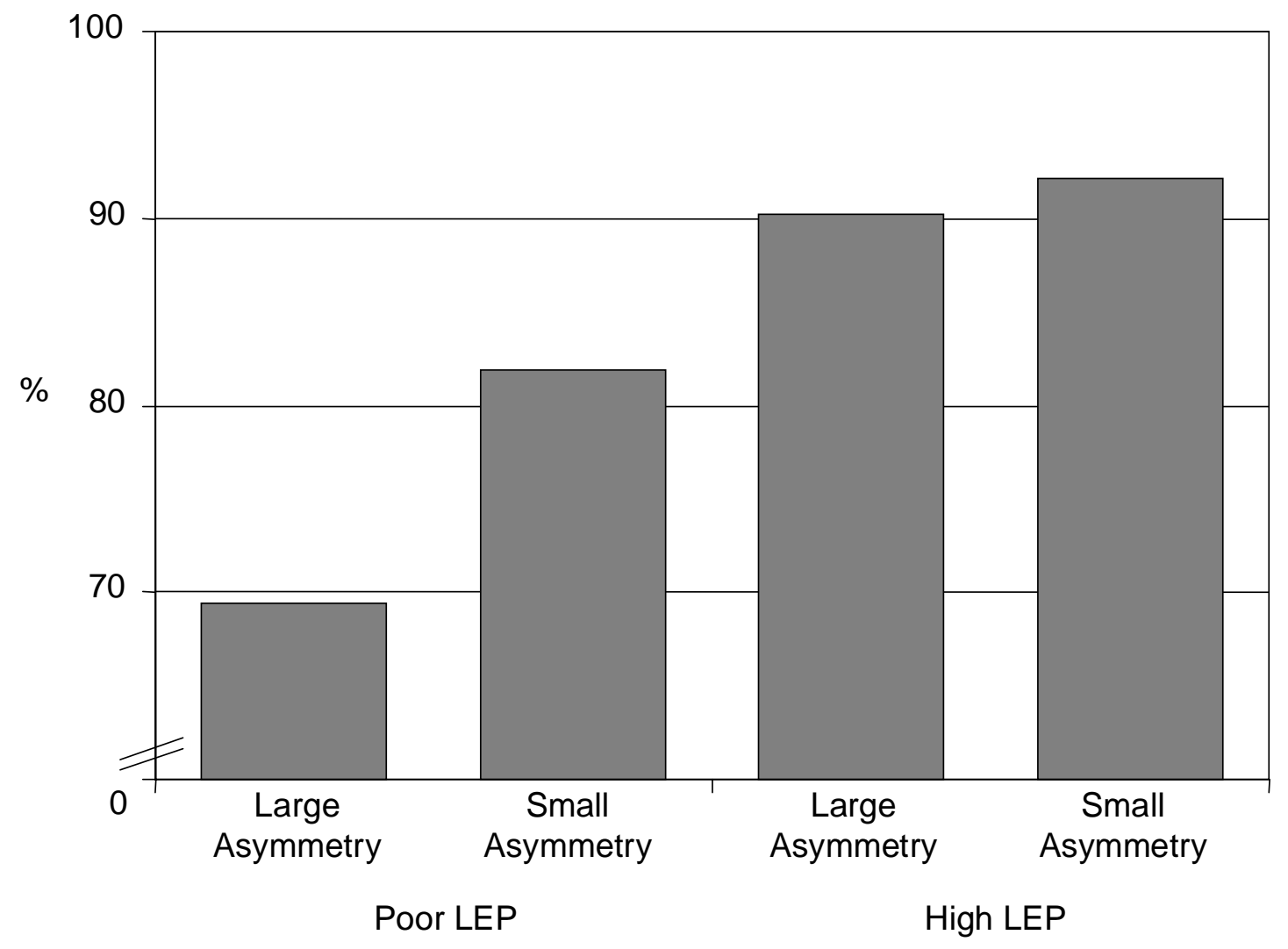

